\title{
Malaria vectors and transmission dynamics in coastal south-western
} Cameroon

\author{
Jude D Bigoga ${ }^{1,2}$, Lucien Manga ${ }^{3}$, Vincent PK Titanji ${ }^{4}$, Maureen Coetzee*5,6 \\ and Rose GF Leke ${ }^{2,7}$
}

Address: ${ }^{1}$ Department of Biochemistry, Faculty of Science, University of Yaounde I, Cameroon, ${ }^{2}$ The Biotechnology Center, University of Yaounde I, P.O. Box 3851-Messa, Yaounde, Cameroon, ${ }^{3}$ Vector Biology and Control Unit, WHO Regional Office for Africa, Brazzaville, Congo, ${ }^{4}$ Department of Life Sciences, Faculty of Science, University of Buea, Cameroon, ${ }^{5}$ Vector Control Reference Unit, National Institute for Communicable Diseases, NHLS, Johannesburg, South Africa, ${ }^{6}$ Division of Virology and Communicable Disease Surveillance, School of Pathology of the National Health Laboratory Service and the University of the Witwatersrand, Johannesburg, South Africa and ${ }^{7}$ Faculty of Medicine and Biomedical Sciences, University of Yaounde I, Cameroon

Email: Jude D Bigoga - judebigoga@yahoo.com; Lucien Manga - mangal@whoafr.int; Vincent PK Titanji - vpktitanji@yahoo.co.uk; Maureen Coetzee* - maureenc@nicd.ac.za; Rose GF Leke - roseleke@yahoo.com

* Corresponding author

Published: 17 January 2007

Malaria Journal 2007, 6:5 doi:10.1186/1475-2875-6-5

This article is available from: http://www.malariajournal.com/content/6/1/5

(C) 2007 Bigoga et al; licensee BioMed Central Ltd.

This is an Open Access article distributed under the terms of the Creative Commons Attribution License (http://creativecommons.org/licenses/by/2.0), which permits unrestricted use, distribution, and reproduction in any medium, provided the original work is properly cited.
Received: 09 November 2006

Accepted: 17 January 2007

\begin{abstract}
Background: Malaria is a major public health problem in Cameroon. Unlike in the southern forested areas where the epidemiology of malaria has been better studied prior to the implementation of control activities, little is known about the distribution and role of anophelines in malaria transmission in the coastal areas.
\end{abstract}

Methods: A 12-month longitudinal entomological survey was conducted in Tiko, Limbe and Idenau from August 200I to July 2002. Mosquitoes captured indoors on human volunteers were identified morphologically. Species of the Anopheles gambiae complex were identified using the polymerase chain reaction (PCR). Mosquito infectivity was detected by the enzyme-linked immunosorbent assay and PCR. Malariometric indices (plasmodic index, gametocytic index, parasite species prevalence) were determined in three age groups ( $<5 \mathrm{yrs}, 5-15 \mathrm{yrs},>I 5 \mathrm{yrs})$ and followed-up once every three months.

Results: In all, 2,773 malaria vectors comprising Anopheles gambiae (78.2\%), Anopheles funestus ( $17.4 \%)$ and Anopheles nili (7.4\%) were captured. Anopheles melas was not anthropophagic. Anopheles gambiae had the highest infection rates. There were 287, 160 and 149 infective bites/person/year in Tiko, Limbe and Idenau, respectively. Anopheles gambiae accounted for $72.7 \%$, An. funestus for $23 \%$ and An. nili for $4.3 \%$ of the transmission. The prevalence of malaria parasitaemia was $41.5 \%$ in children $<5$ years of age, $31.5 \%$ in those $5-15$ years and $10.5 \%$ in those $>15$ years, and Plasmodium falciparum was the predominant parasite species.

Conclusion: Malaria transmission is perennial, rainfall dependent and An. melas does not contribute to transmission. These findings are important in the planning and implementation of malaria control activities in coastal Cameroon and West Africa. 


\section{Background}

Malaria is a major public health problem in Cameroon [1$3]$. Over 900,000 clinical cases occur yearly and are responsible for $40-45 \%$ hospital consultations, $20 \%$ hospital admissions and 35-40\% deaths. Children less than five years old are the most affected [4]. Despite efforts made by the National Malaria Control Programme to curb the disease burden, the prevalence is seemingly on the increase. Previous studies have attributed this to the increasing spread of drug resistance in the parasite, insecticide resistance in the vectors, inadequate and inconsistent allocation of resources for control [5,6] and the presence of very efficient mosquito vectors of Plasmodium falciparum [7-9].

Malaria vector control activities in Cameroon focus mainly on the use of insecticide-treated bed nets. However, the implementation of effective vector control strategies requires requisite information on the vector population structure, their distribution and efficiency in malaria transmission. Previous studies in Cameroon have shown that the intensity and duration of transmission, as well as the vector species, vary greatly between different eco-zones of the country, from perennial transmission in the southern forested regions to seasonal and unstable transmission in the northern Sudano-savannah and Sahelian savannah regions [8-13]. At least 14 out of the 45 species of Anopheles described in Cameroon are capable of transmitting malaria. The most common and efficient vector species are Anopheles gambiae, Anopheles. arabiensis Anopheles funestus, Anopheles nili and Anopheles moucheti [14]. Species such as Anopheles paludis, Anopheles pharoensis and Anopheles hankocki play only minor, secondary roles in malaria transmission $[8,15]$.

Although Anopheles melas, a member of the An. gambiae complex, is purported to be an important malaria vector along the coast of many West African countries, its importance in malaria transmission in Cameroon is not clear. Although few studies have reported on the occurrence of An. melas in Cameroon [16], currently there is insufficient information on its abundance and infection rates. This may be due, in part, to the fact that early studies on An. gambiae s.l. relied on morphological identification only and more recent studies have not used modern methods like PCR because they are expensive and expertise demanding.

Unlike in the southern forested and northern savannah regions of Cameroon, where the epidemiology of malaria has been better studied prior to the implementation of malaria control activities, very little is known about the vectors and their contribution to malaria transmission in the coastal areas. The coastal area of south-west Cameroon is a characteristic ecological area. It has undergone serious environmental modifications over the years owing to rapid growth in population, urbanization and the agroindustrial activities of the Cameroon Development Corporation (CDC), the largest agricultural scheme in central Africa. Such modifications can lead to ecological changes that affect the vector population structure, distribution and density, all of which would impact on the efficiency in transmitting malaria. Thus, this paper describes the anopheline species composition and malaria transmission dynamics in three localities (Tiko, Limbe and Idenau) along the Atlantic coast of south-western Cameroon.

\section{Methods}

\section{Description of the study area}

The study was conducted in Tiko (Small Ikange) $4^{\circ} 04^{\prime} \mathrm{N}$, $9^{\circ} 17^{\prime} \mathrm{E}$ - a rural setting; Limbe (Middle Farm) $4^{\circ} 02^{\prime} \mathrm{N}$, $9^{\circ} 11^{\prime} \mathrm{E}$ - a cosmopolitan town; and Idenau (BibundeScipio) $4^{\circ} 01^{\prime} \mathrm{N}, 9^{\circ} 03^{\prime} \mathrm{E}$ - a semi-urban vicinity situated along the Atlantic coast of Cameroon. Idenau borders the Atlantic Ocean; while Tiko is situated $20 \mathrm{~km}$ from Limbe, $50 \mathrm{~km}$ from Idenau and $19 \mathrm{~km}$ from the coastline. Limbe is situated $30 \mathrm{~km}$ from Idenau and $8 \mathrm{~km}$ from the coastline. The area lies within the tropical rain forest region of Central Africa and harbours the largest agro-industrial scheme in the country and sub region, the Cameroon Development Corporation (CDC). Crops grown in the plantations include rubber (Fiscus elastica) and banana (Musa spp.) in Tiko, and oil palm (Elaies Spp.) in Tiko, Limbe and Idenau. Plantation workers are housed in camps with few medical facilities at their disposal. The population is highly heterogeneous comprising people from almost every ethnic community in Cameroon, some parts of neighbouring Nigeria, Niger and Ghana. The climate is typically equatorial with a mean annual temperature of $26^{\circ} \mathrm{C}$, mean annual rainfall of 2,000-10,000 mm and $88 \%$ relative humidity. There are two seasons; the dry season from November to February and the wet season from March to October.

\section{Study design and ethical considerations}

A longitudinal study was carried out for 12 months from August 2001 to July 2002. Permission to carry out this study was obtained from the Human Resources and Health departments of the Cameroon Development Corporation (CDC), and an ethical clearance obtained from the National Ethical Review Committee of Cameroon. A sensitization rally was organized with the population during which the purpose of the study was clearly explained. Participation in the study was voluntary. All diagnosed cases of malaria were treated for free, following recommendations set by the national malaria control program.

\section{Collection and processing of adult mosquitoes specimens}

For two consecutive nights (6:00 pm-6:00 am) every month, at each site (total 72 nights), mosquitoes were 
captured indoors on six human volunteer collectors using the human landing catch method. These were sorted and the anophelines morphologically identified to groups using the taxonomic keys of Gillies and De Meillon [17] and Gillies and Coetzee [18]. The ovaries of a random sample of unfed specimens were extracted and examined for parity determination [19]. The carcasses of each dissected and those undissected mosquitoes were individually preserved on cotton wool over a desiccant (silica gel) in labeled tubes for the necessary immunological and molecular biologic analyses.

\section{Larval collection, rearing and processing of adult Anopheles gambiae}

Anopheles gambiae larvae were collected from potential breeding sources by dipping. The larvae were graded into different breeding containers according to whether they were in their first, second, third or fourth instars. The larvae were fed with finely ground dog biscuit until the adults emerged. The emerging adults were maintained on $10 \%$ sugar solution until identified to species level by polymerase chain reaction (PCR) as described by Scott et al. [20].

\section{PCR identification of the Anopheles gambiae complex} In cases where the number of An. gambiae mosquitoes collected per month exceeded 40, the legs and wings of at least 40 were used for species identification by the polymerase chain reaction method [20]. Positive control mosquitoes for An. melas, An. gambiae s.s., An. arabiensis and Anopheles quadriannulatus (obtained from the National Institute for Communicable Diseases, Johannesburg, South Africa) and negative controls (tubes containing all the components of a PCR reaction mixture but without template DNA) were assayed simultaneously. Anopheles gambiae specimens were identified to molecular $\mathrm{M}$ or $\mathrm{S}$ form as described by Favia and others [21].

\section{ELISA for detection and PCR for confirmation of parasite infections in mosquitoes}

The head and thorax of each mosquito were separated from the rest of the body, homogenized in blocking buffer (0.5\%Casein, $0.1 \mathrm{~N} \mathrm{NaOH}, 1 \times \mathrm{PBS}$ ) and a portion of the homogenate assayed by ELISA for the presence of circumsporozoite antigens (CSA) of P. falciparum, Plasmodium malariae, Plasmodium ovale and two Plasmodium vivax strains (Pv210 and Pv247) [22,23]. Positive controls (Kikergaard \& Perry Laboratories, USA) and negative controls (uninfected laboratory reared mosquitoes) were assayed simultaneously. A specimen was considered positive if a visual green colour was detected with an OD value (at 405 $\mathrm{nm}$ ) of at least the mean of the negative controls plus two standard deviations [24]. Plasmodium DNA was extracted from the remainder of the head-thorax homogenate of all ELISA positive specimens using phenol and examined for sporozoites by PCR $[25,26]$. To minimize having false positive ELISA $[27,28]$ only PCR confirmed specimens were used to determine the infection rates. Sporozoite densities and Sporozoite antigen equivalencies were estimated using standard graphs for estimating sporozoite numbers from absorbance values provided with the ELISA kit.

\section{Malaria prevalence survey}

Malaria prevalence surveys were conducted four times in the human population: in August 2001 (rainy season), November 2001 (transition: rainy to dry season), February 2002 (dry season) and May 2002 (transition: dry to rainy season), in a cohort of subjects from thirty randomly selected homes at each study site. Thick and thin blood smears were made using finger prick blood samples. The blood smears were fixed in methanol (thin smears only), and stained with Diff-quick stain (Baxter International, Deerfield, IL, USA). The thick smears were independently examined for the presence of malaria parasites by two microscopists (unaware of each other's results). An individual was considered positive if malaria parasites were detected in the blood smear. A blood smear was considered negative if parasites were not detected after examining 200 oil-immersion fields of the thick smear. When malaria parasites were detected in a blood film, the parasite density was determined by counting the number of parasites present per 200 white blood cells in a thick smear and multiplying by 40 to arrive at an approximate parasite count per microlitre of blood. This was based on the assumption that the average WBC count was $8,000 / \mu \mathrm{l}$ blood [29]. The gametocyte index was calculated as the proportion of positive slides containing gametocytes after examining 200 oil-immersion fields. The thin smears were examined to identify the Plasmodium species. However, species identification was further confirmed by PCR, using Plasmodium DNA isolated by the chelex method from a portion of each blood sample collected on filter paper [30].

\section{Data analysis}

The total number of mosquitoes collected, irrespective of the species, was used to assess the level of nuisance to man. Entomological parameters considered were: 1) Manbiting rate ( $\mathrm{ma}$ ), calculated as the average number of bites received per person per night of collection; 2) Infection rate, measured as the proportion of mosquitoes found to contain circum-sporozoite antigen by ELISA. 3) Parity rate, measured as the ratio of parous mosquitoes to the sum total of parous and nulliparous mosquitoes dissected. 4) Entomological Inoculation Rate (EIR), which was calculated as the product of the man biting rate and circumsporozoite antigen rate as confirmed by PCR. Sporozoite densities and Sporozoite antigen equivalencies were estimated using standard graphs provided with the 
ELISA kit. Chi-square statistics was used to compare the number of mosquitoes at different sites and CSA rates.

\section{Results}

\section{Composition of mosquito species biting humans}

A total of 3,852 mosquitoes were collected during 432 human nights at the three localities. The species found were An. gambiae (57\%), An. funestus (10\%) and An. nili $(5 \%)$ as the malaria vectors, and Anopheles rufipes (9\%), Culex spp. (17\%) and Mansonia spp. (2\%) as non-malaria vectors. Table 1 shows the distribution of mosquito species by locality. Amongst the 2,773 female Anopheles vectors of malaria collected $79 \%$ were An. gambiae, 14\% An. funestus and $7 \%$ An. nili. The density of anopheline species followed trends in rainfall patterns, peaking during periods of heavy rainfall especially between July and September (Figure 1).

Out of the 2,168 An. gambiae collected feeding on humans, all 1,240 identified by PCR were An. gambiae s.s. and only the M molecular form was detected. No $A n$. melas was identified amongst specimens caught biting humans at all three localities. Adult An. gambiae complex mosquitoes bred from larval collections were identified as An. gambiae s.s. $\mathrm{M}$ form (85.6\%) and An. melas (14.4\%) with the latter species found only in Limbe and Idenau (Table 2).

\section{Parity rates}

Table 3 gives the parity rates of the malaria vectors in the three localities. The overall parity rate was $64.2 \%(\mathrm{n}=$ 1520). Generally, An. gambiae had very high parity rates at all the localities, although there were more parous An. nili in Tiko $(75.8 \%)$. The parity rates were observably higher during the dry season with peak monthly feeding for the parous mosquitoes consistently between 24:00 and 02:00 hours. The number of An. funestus mosquitoes collected in Limbe and Idenau was too small for statistical analysis.

\section{Biting rates and seasonality}

The mean daily biting rate was highest for An. gambiae (Table 4). Where An. nili was found, particularly in Tiko, peak biting was in May, while An. funestus peaked in March. The mean daily biting rates (bites/person/night) varied seasonally, increasing with the amount of rainfall (Figure 2). The peak bite rate was recorded during August, in the peak of the rainy season. The frequency of human attack at night was observed to increase gradually between 20:00 and 22:00 hours, then peaking between 22:00 and 02:00 hours and then declining speedily towards dawn. The biting rate was generally higher in Tiko.

\section{Vector infection rates}

Details of the mean CSA rates and monthly variation by locality and by vector species are shown in Table 4 and
Figure 3. When the 2,773 female Anopheles mosquitoes were examined by ELISA only, 298 (10.7\%) were found to be infected. Following PCR on the positive ELISA specimens, $263(9.48 \%)$ out of the 298 were positive for either $P$. falciparum or P. malariae or both $(88.3 \%$ confirmation rate). Of these, there were $8.3 \%$ infections in An. gambiae, $17.8 \%$ in An. funestus and $6.3 \%$ in An. nili. Generally, An. funestus had higher CSA rates compared with An. gambiae and $A n$. nili, where they co-existed. CSA rates of up to $40 \%$ were recorded between June and October, during the rainy season.

Of the 263 PCR-confirmed infections detected in the vectors, $90 \%$ were $P$. falciparum and $10 \%$ P. malariae. Neither $P$. ovale nor $P$. vivax infections were found in the mosquitoes. Only $5 \%$ of the mosquitoes (all An. gambiae) carried mixed Plasmodium infections. There were more infected An. gambiae during the wet season, maintaining low but similar proportions throughout the other months of the year. The estimated mean sporozoite density for all positive anophelines was 1,200 for $P$. falciparum infections and 400 for $P$. malariae, while the antigen equivalence was $37.5 \mathrm{pg}$ for $P$. falciparum and $12.5 \mathrm{pg}$ for P. malariae.

In Tiko, 142 infections were detected, 77 in An. gambiae ( $91 \%$ P. falciparum and $9 \%$ P. malariae), 52 in An. funestus (92.3\% P. falciparum and 7.7\% P. malariae) and 13 in An. nili (all $P$. falciparum). No cases of mixed infections were found. In Limbe, there were $8.4 \%(n=619)$ infections in An. gambiae, $11.4 \%(\mathrm{n}=79)$ in An. funestus and none in An. nili. The highest number of infections $(28.5 \%)$ was recorded in January and in April. Infected An. funestus were found only during three months (September, January and July). The difference between the CSA rates for $A n$. funestus and An. gambiae in Limbe was not significant $(\mathrm{p}=$ $0.3)$. In Idenau, there were $10.8 \%(\mathrm{n}=463)$ infections in An. gambiae and 10/15 in An. funestus. Infections in An. gambiae were found only during the rainy season, increasing steadily from the onset of the rains and peaking in September (33.3\%).

\section{Entomological inoculation rates (EIR)}

Details of the number of infective bites/person/year (ib/p/ y) by vector species in the three localities are presented in Table 4 . Figure 4 shows the monthly variation in the combined EIRs for the vector species in the surveyed areas. The annual EIR in Tiko was $287 \mathrm{ib} / \mathrm{p} / \mathrm{y}$, where An. gambiae was the main vector species and was responsible for 177 [95\%CI: 161.0-193.1] ib/p/y. It contributed to transmission every month of the year and more intensely during the rainy season, with a peak in August $(56 \mathrm{ib} / \mathrm{p} / \mathrm{m})$. Anopheles funestus and An. nili were the secondary vectors, with An. funestus transmitting malaria only during the rainy season with a peak in September $(33 \mathrm{ib} / \mathrm{p} / \mathrm{m})$. In Limbe and Idenau, where An. gambiae and An. funestus 
Table I: Distribution of the mosquito populations biting humans by study locality in coastal Cameroon.

\begin{tabular}{|c|c|c|c|c|c|}
\hline & Mosquito species & Tiko & Limbe & Idenau & Total Collected \\
\hline \multirow[t]{3}{*}{ Malaria vectors } & Anopheles gambiae & $1086(51 \%)$ & $619(56.5 \%)$ & 463 (74.5\%) & 2168 \\
\hline & Anopheles funestus & $305(14 \%)$ & 79 (7.2\%) & $15(2.5 \%)$ & 399 \\
\hline & Anopheles nili & $205(10 \%)$ & I & - & 206 \\
\hline \multirow[t]{4}{*}{ Non-malaria vectors } & Anopheles rufipes & $334(16 \%)$ & $23(2 \%)$ & - & 357 \\
\hline & Culex sp. & $135(6 \%)$ & 365 (33.3\%) & 135 (21.7\%) & 635 \\
\hline & Mansonia sp. & $70(3 \%)$ & $9(1 \%)$ & $8(1.3 \%)$ & 87 \\
\hline & Total & $2135(100 \%)$ & $1096(100 \%)$ & $621(100 \%)$ & 3852 \\
\hline
\end{tabular}

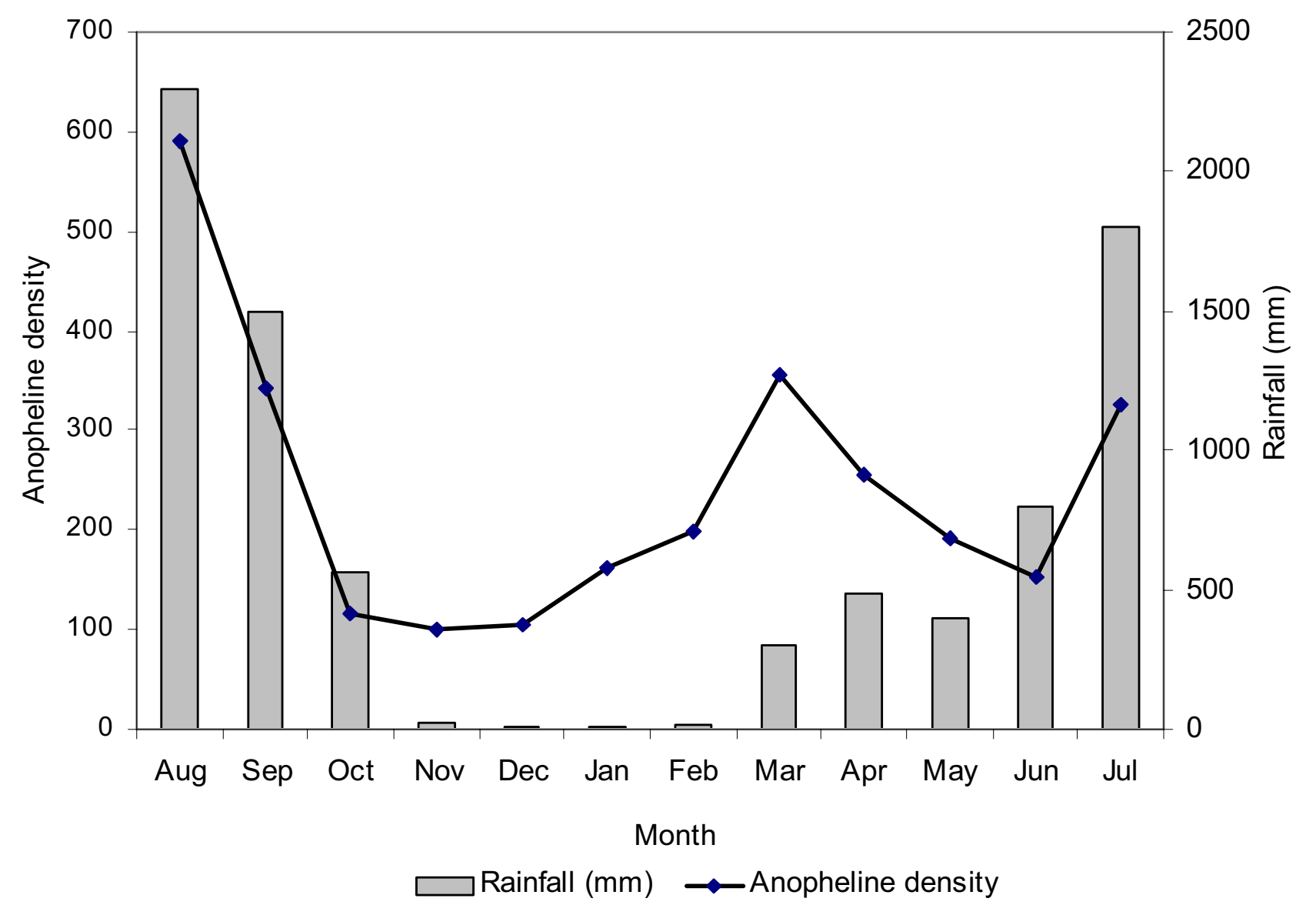

Figure I

Monthly variation in the density of anopheline vectors of human malaria (line) in relation to rainfall (bars). 
Table 2: Distribution of Anopheles gambiae complex adults caught feeding on humans and bred from larval collections in Tiko, Limbe and Idenau, coastal Cameroon.

\begin{tabular}{|c|c|c|c|c|c|c|c|c|}
\hline \multirow{3}{*}{ Locality } & \multicolumn{4}{|c|}{ Adult Anopheles gambiae feeding on humans } & \multicolumn{4}{|c|}{ An gambiae bred from larval collections } \\
\hline & \multirow{2}{*}{$\begin{array}{c}\text { Total } \\
\text { collected }\end{array}$} & \multirow{2}{*}{$\begin{array}{c}\text { Total } \\
\text { examined by } \\
\text { PCR }\end{array}$} & \multicolumn{2}{|c|}{ Anopheles gambiae s.s } & \multirow{2}{*}{$\begin{array}{c}\text { Total } \\
\text { examined By } \\
\text { PCR }\end{array}$} & \multicolumn{2}{|c|}{ Anopheles gambiae s.s. } & \multirow{2}{*}{$\begin{array}{c}\text { Anopheles } \\
\text { melas }\end{array}$} \\
\hline & & & M form & $S$ form & & $M$ form & S form & \\
\hline Tiko & 1086 & 540 & $540(100 \%)$ & 0 & 60 & $60(100 \%)$ & 0 & 0 \\
\hline Limbe & 619 & 400 & 400 (100\%) & 0 & 60 & $52(86.7 \%)$ & 0 & $8(13.3 \%)$ \\
\hline Idenau & 463 & 300 & $300(100 \%)$ & 0 & 60 & $42(70 \%)$ & 0 & $18(30 \%)$ \\
\hline Total & 2168 & 1240 & 1240 (1 00\%) & 0 & 180 & $154(85.6 \%)$ & 0 & $26(14.6 \%)$ \\
\hline
\end{tabular}

were the only vectors, An. gambiae was predominant and responsible for 133/160 [95\%CI: $123.7-142.2$ ] ib/p/y in Limbe and for 124/149 [95\%CI: $115.0-132.9] \mathrm{ib} / \mathrm{p} / \mathrm{y}$ in Idenau. Peak transmission in Idenau was in July, during the rainy season.

\section{Malaria prevalence survey}

Plasmodic index (PI)

The prevalence by age group was $41.5 \%(n=595)$ for those less than 5 years of age, $31.5 \%(n=923)$ for those $5-15$ years old and $10.5 \%(n=172)$ for those older than 15 years (Figure 5). The plasmodic index in Tiko was 39\% $(\mathrm{n}=587)$ and distributed as $50.7 \%, 40.4 \%$ and $12 \%$ for the age groups $<5$ years, $5-15$ years and $>15$ years respectively. The highest number of cases $(67 / 164)$ was recorded in May, in the early parts of the rainy season and least in November (38/126), the transition from rainy to dry season. The plasmodic index in February was $44.9 \%$ ( $\mathrm{n}=$ $127)$ and in August $36 \%(n=200)$. A significant difference was observed in the between season plasmodic indices $(\mathrm{p}=0.04)$.

The plasmodic index in Limbe was $25.3 \%(\mathrm{n}=689)$ distributed as $22.2 \%, 21.5 \%$ and $15 \%$ in the $<5$ years, $5-15$ years $>15$ years respectively. The prevalence during each sampling period was 22.6\% $(n=208)$ in August, $20.6 \%$ $(\mathrm{n}=247)$ in November, $20.9 \%(\mathrm{n}=116)$ in February and $21.2 \%$ (25/118) in May. The difference between sampling periods was not significant $(\mathrm{p}=0.9)$. The prevalence in Idenau was $42.7 \%(\mathrm{n}=174)$. The most affected were the age group $<5$ years old with a prevalence of $54 \%$. The age group 5-15 years had a prevalence of $39 \%(n=213)$. No infections were found in persons older than 15 years.

\section{Parasite species}

Infections were detected as either single infections of $P$. falciparum only, mixed infections of $P$. falciparum and $P$. malariae or a cocktail of $P$. falciparum, $P$. malariae and $P$. ovale. Plasmodium falciparum alone accounted for $85 \%$ of all infections detected. There were $14 \%$ cases of mixed infections of $P$. falciparum and P. malariae and $1 \%$ mixed infections of the three parasites.

A total of 121 infected cases were detected in Tiko with $83.5 \%$ single infections of only $P$. falciparum, $11.6 \%$ mixed $P$. falciparum and $P$. malariae infections and $4.9 \%$ triple infections of $P$. falciparum, $P$. malariae and $P$. ovale. At least $50 \%$ of all cases in Tiko during each sampling period were children less than five years old. In Limbe, $88 \%(\mathrm{n}=110)$ of the infections were $P$. falciparum alone. There were, $10 \%$ mixed infections of $P$. falciparum and $P$. malariae, and $1.8 \%$ mixed infections of $P$. falciparum, $P$.

Table 3: Parity rates of the malaria vectors at the three study sites.

\begin{tabular}{|c|c|c|c|}
\hline Study site & Total No. Dissected & Species & Parity rate \\
\hline \multirow[t]{3}{*}{ Tiko } & 823 & An. gambiae & $65.2 \%(n=528)$ \\
\hline & & An. funestus & $54.3 \%(n=175)$ \\
\hline & & An. nili & $75.8 \%(n=120)$ \\
\hline \multirow[t]{2}{*}{ Limbe } & 397 & An. gambiae & $63.8 \%(n=35 I)$ \\
\hline & & An. funestus & $56.5 \%(n=46)$ \\
\hline \multirow[t]{2}{*}{ Idenau } & 300 & An. gambiae & $69.4 \%(n=285)$ \\
\hline & & An. funestus & $53.3 \%(n=15)$ \\
\hline
\end{tabular}


Table 4: Mean daily man biting rates ( $\mathrm{ma}$ ), circumsporozoite antigen rates (CSA) and entomological inoculation rates (EIR - infective bites per person per year) of the malaria vectors by locality in coastal Cameroon.

\begin{tabular}{|c|c|c|c|c|}
\hline Locality & & Anopheles gambiae & Anopheles funestus & Anopheles nili \\
\hline \multirow[t]{5}{*}{ Tiko } & Total collected & 1086 & 305 & 205 \\
\hline & $m a$ & 7.5 & 2.1 & 1.4 \\
\hline & Tested for CSP & 1086 & 305 & 205 \\
\hline & CSA rate & $7.1 \pm 1.5 \%$ & $17 \pm 4.2 \%$ & $6.3 \pm 3.3 \%$ \\
\hline & $\operatorname{EIR}[95 \% \mathrm{Cl}]$ & $177[161.0-193.1]$ & $85[69.8-100.1]$ & $24[14.8-33.2]$ \\
\hline \multirow[t]{5}{*}{ Limbe } & Total collected & 619 & 79 & - \\
\hline & $m a$ & 4.3 & 0.6 & - \\
\hline & Tested for CSP & 619 & 79 & - \\
\hline & CSA rate & $8.4 \pm 2.0 \%$ & $1 \mathrm{II} \pm 7.0 \%$ & - \\
\hline & $\operatorname{EIR}[95 \% \mathrm{Cl}]$ & 133 [|23.7-|42.2] & 27 [22.4-31.68] & - \\
\hline \multirow[t]{5}{*}{ Idenau } & Total collected & 463 & 15 & - \\
\hline & $m a$ & 3.2 & 0.1 & - \\
\hline & Tested for CSP & 463 & 15 & - \\
\hline & CSA rate & $10.8 \pm 2.8 \%$ & $10 / 15$ & - \\
\hline & $\operatorname{EIR}[95 \% \mathrm{Cl}]$ & $124[1 \mid 5.0-132.9]$ & $25[16.9-33.9]$ & - \\
\hline
\end{tabular}

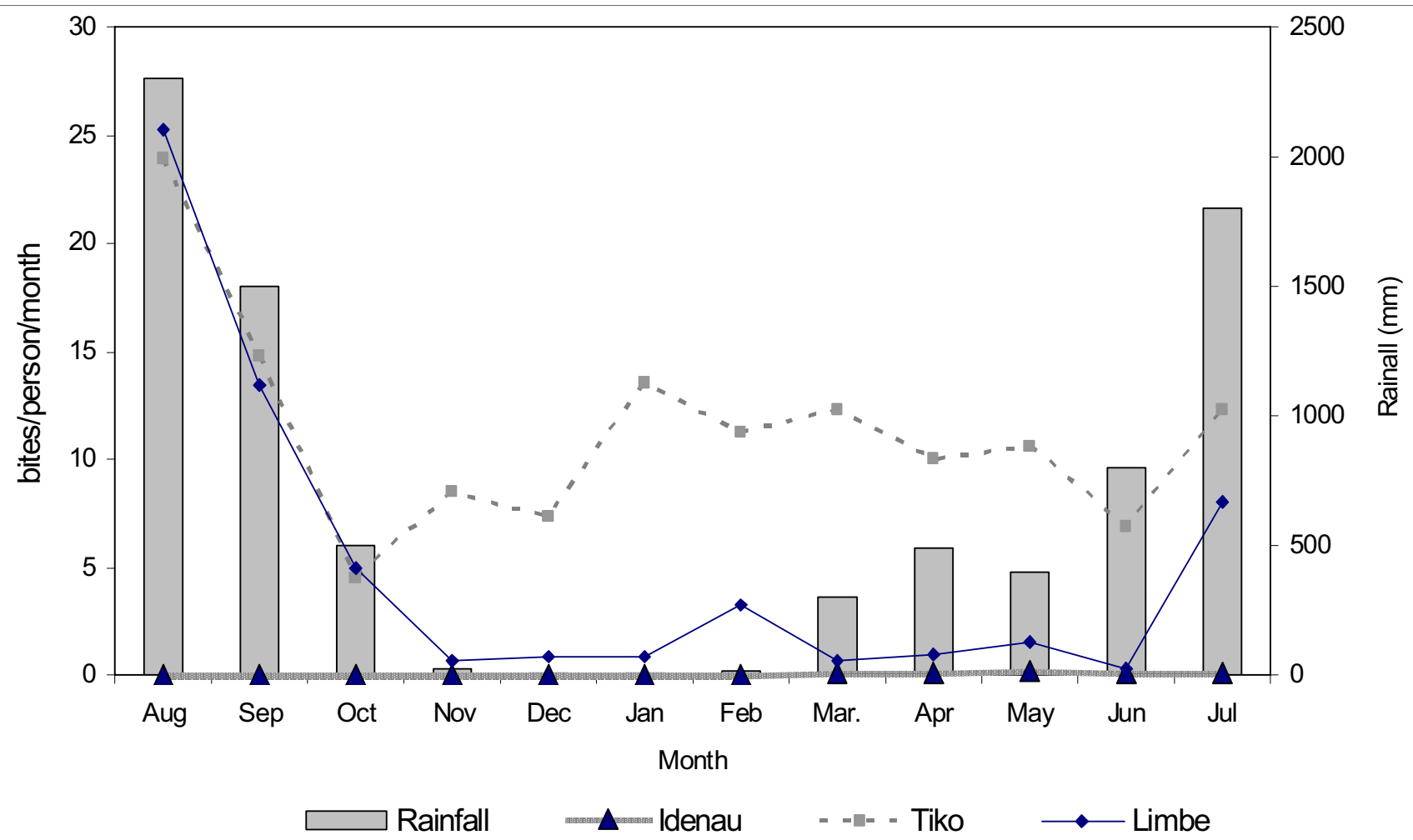

Figure 2

Relationship between rainfall and biting rate of the vectors in the three localities.

malariae and P. ovale. A total of 129 infected cases were 


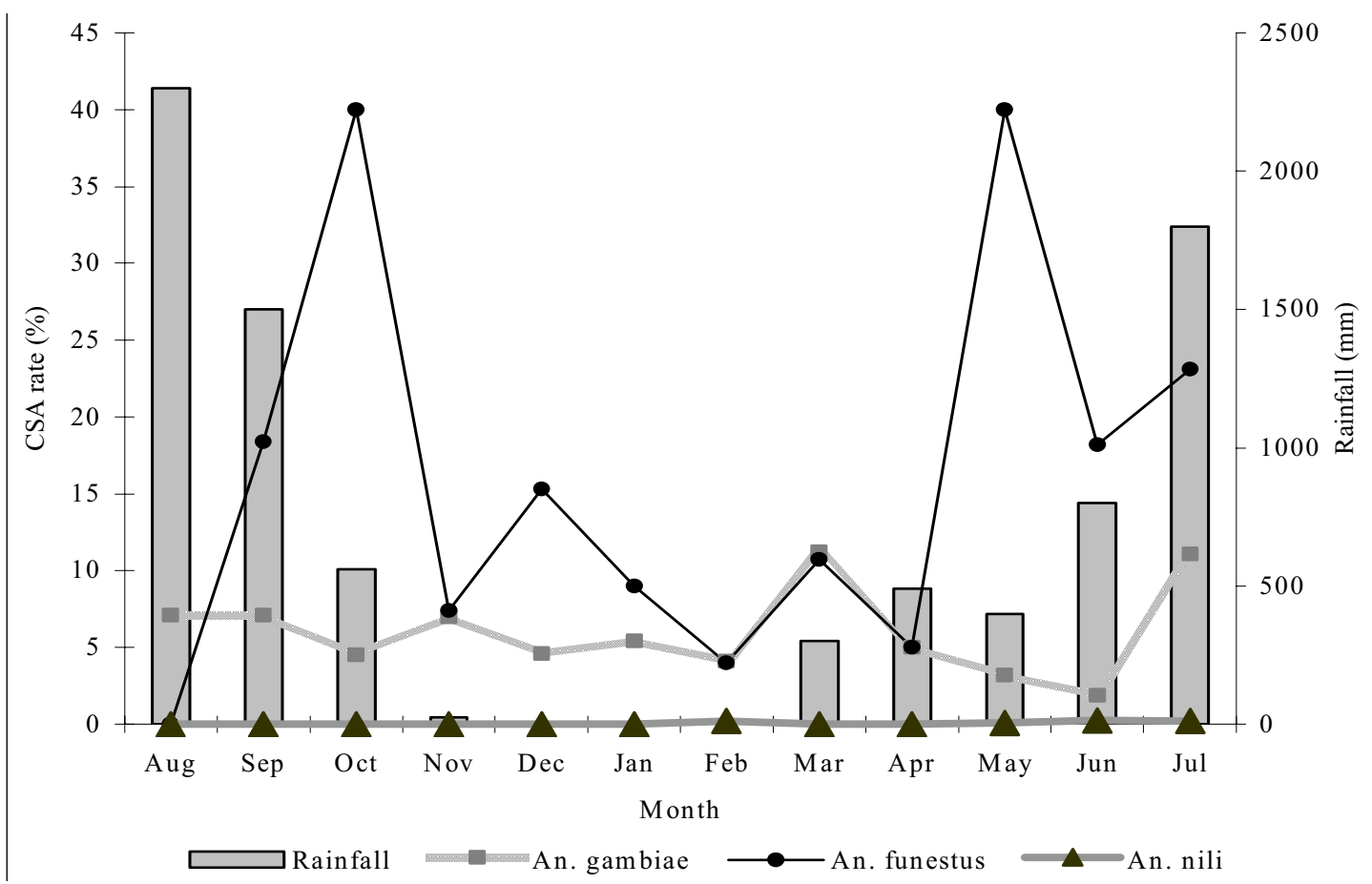

Figure 3

Combined monthly circumsporozoite antigen rates for Anopheles gambiae, An. funestus and An. nili in relation to rainfall in Tiko, Limbe and Idenau.

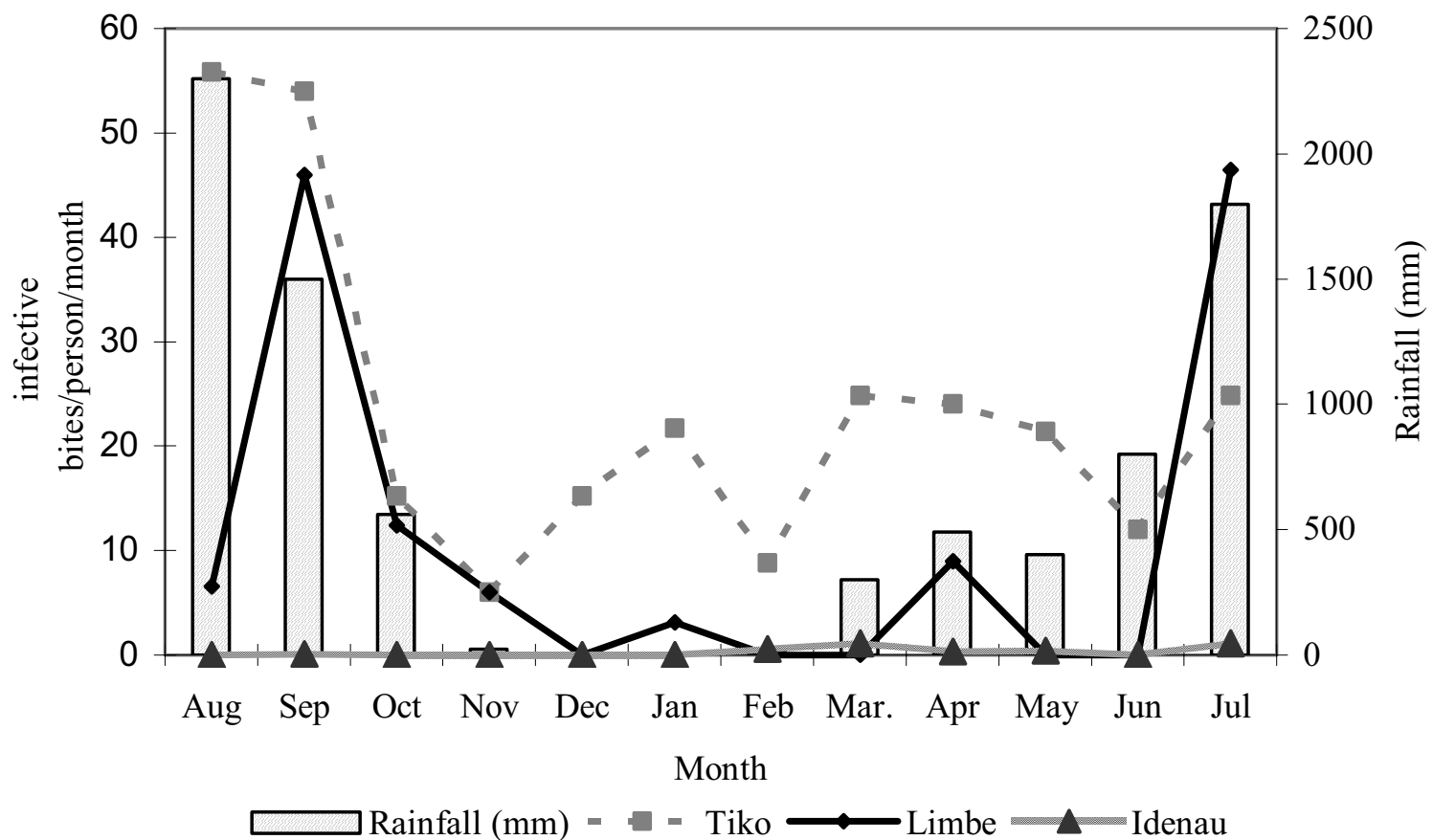

Figure 4

Combined monthly Entomological Inoculation Rates for the vector species in Tiko, Limbe and Idenau. 


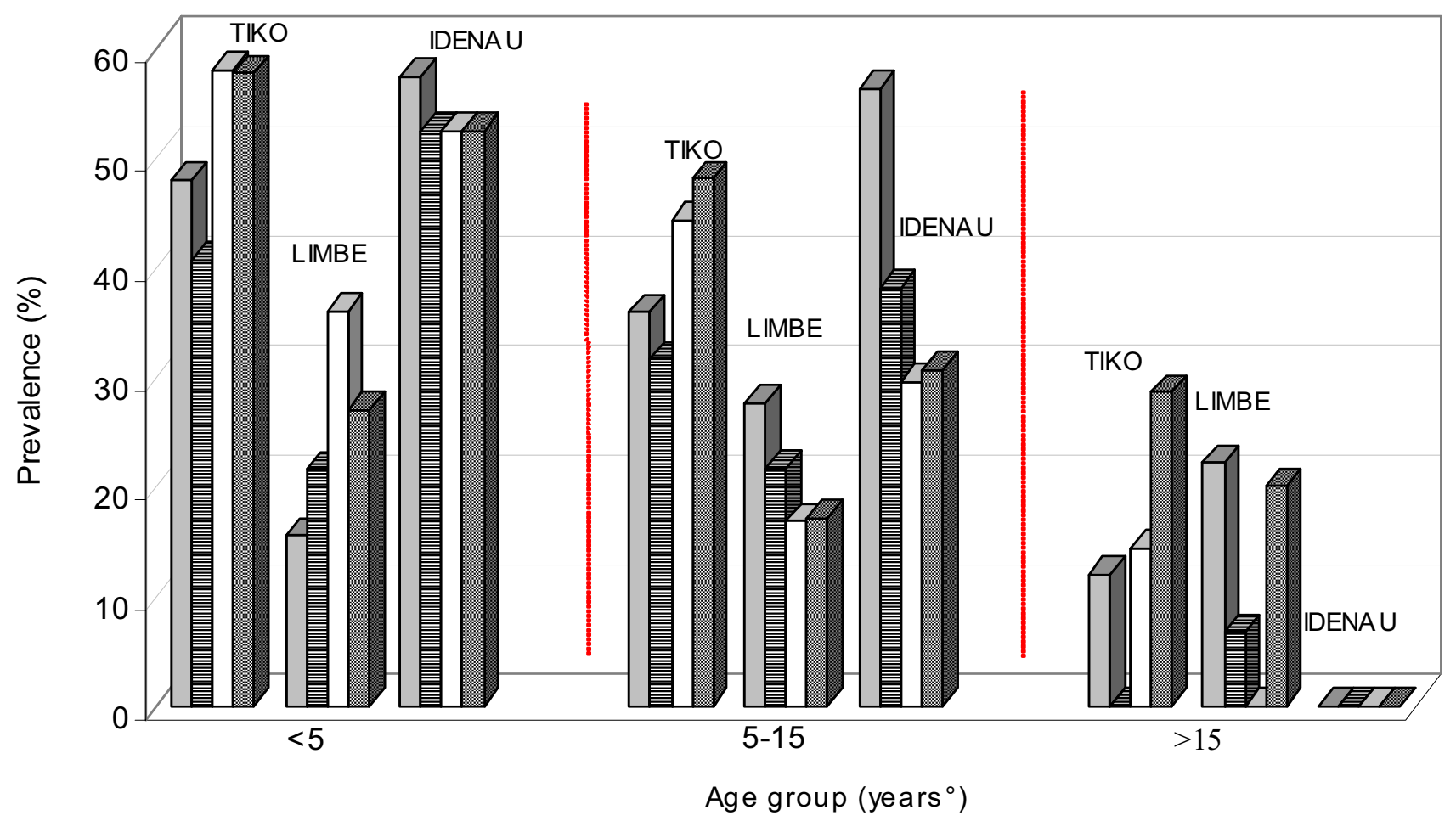

$\square$ Aug 2001 冒Nov 2001ㅁ $\square$ Feb 2002 May 2002

\section{Figure 5}

Prevalence of malaria parasitaemia by age group and season in Tiko, Limbe and Idenau.

detected in Idenau of which $92.2 \%$ were single infections of $P$. falciparum, $6.2 \%$ mixed infections of $P$. falciparum and $P$. malariae and $1.4 \%$ mixed infections of $P$. falciparum, P. malariae and P. ovale.Gametocyte index

The mean gametocyte index was $2.7 \%(\mathrm{n}=1691)$. All gametocytes were identified as $P$. falciparum and mostly in children less than five years of age. Table 5 shows the dis- tribution of the mean gametocyte index at the three localities.

\section{Parasite density}

Slide examination was done independently by two microscopists and the mean parasite density considered. Where the difference in parasite density was more than 20 parasites/ $\mu \mathrm{l}$, the slide was read by a third person and the mean of the two nearest values considered. In Tiko, the mean

Table 5: Distribution of the mean gametocyte index in children under 5 years by locality in coastal Cameroon.

\begin{tabular}{|c|c|c|c|c|}
\hline \multirow[t]{2}{*}{ Season } & \multicolumn{3}{|c|}{ Locality } & \multirow[t]{2}{*}{ Total } \\
\hline & Tiko & Limbe & Idenau & \\
\hline $\begin{array}{l}\text { August 200I (Rainy } \\
\text { Season) }\end{array}$ & $4 / 200(2.0 \pm 0.1 \%)$ & $3 / 208(1.4 \pm 0.1 \%)$ & $4 / 120(3.3 \pm 0.1 \%)$ & $1 \mathrm{I} / 528(2.1 \%)$ \\
\hline $\begin{array}{l}\text { November 200I } \\
\text { (Transition:Rainy-dry } \\
\text { season) }\end{array}$ & $4 / 134(3.0 \pm 0.1 \%)$ & $3 / 118(2.5 \pm 0.1 \%)$ & $6 / 95(6.3 \pm 0.1 \%)$ & 13/347 (3.7\%) \\
\hline $\begin{array}{l}\text { February } 2002 \text { (Dry } \\
\text { season) }\end{array}$ & $5 / 127(4.0 \pm 0.1 \%)$ & $2 / 116(1.7 \pm 0.1 \%)$ & $3 / 94(3.2 \pm 0.1 \%)$ & $10 / 337(3.0 \%)$ \\
\hline $\begin{array}{l}\text { May } 2002 \text { (Transition: dry- } \\
\text { Rainy season) }\end{array}$ & $3 / 126(2.4 \pm 0.1 \%)$ & $3 / 247(1.2 \pm 0.1 \%)$ & $4 / 106(3.8 \pm 0.1 \%)$ & $10 / 479(2.1 \%)$ \\
\hline
\end{tabular}


parasite count throughout the four sampling periods was 6,035 parasites/ $\mu$ l of blood. The highest count $(103,000 /$ $\mu \mathrm{l})$ was determined in a two-year old in November, the end of the rains. In Limbe, the mean parasite count during the four sampling periods was $6,103 / \mu \mathrm{l}$ of blood and the highest count $(90,000 / \mu \mathrm{l})$ was detected in a one-year-old in May, during the rainy season. The mean parasite count in Idenau was $4,098 / \mu \mathrm{l}$ with the highest count observed in a one year old in May $(56,000 / \mu \mathrm{l})$ at the onset of the rains.

\section{Discussion}

The findings of this study show clearly that malaria transmission in coastal south-west Cameroon is perennial with the intensity increasing with the prevalence of parasitaemia and amount of rainfall. The human population is therefore constantly exposed to infective mosquito bites that result in the development and maintenance of naturally acquired immunity [31]. As shown, an individual living in Tiko, Limbe and Idenau will on the average receive 287, 160 and 149 infective mosquito bites/year respectively. The prevalence of malaria parasitaemia was inversely related to age. The absence of malaria parasites in persons older than 15 years in Idenau is paradoxical, and may not be fully justified since only 11 individuals belonging to this age group accepted to be part of the study in this locality. The fact that gametocytes were found mainly in children less than five years of age suggests this age group as the major parasite reservoir for malaria vectors. Compared to the high CSA rates obtained, the gametocyte index was unexpectedly low. It is suggested that many of the participants might have been exposed to antimalarial drugs prior to the survey that resulted in the low gametocyte index.

Anopheles gambiae s.s. M molecular form, An. funestus and An. nili were the main malaria vectors in the surveyed areas with An. gambiae being predominant and the most aggressive. This observation in Tiko, a rural settlement, is different from that in the rural areas of southern-forested Cameroon where An. gambiae has been reported not to be the major malaria vector $[32,33]$. Anopheles nili was conspicuously present only in Tiko. Anopheles funestus was present in all three localities in low numbers, but generally had higher infection rates. This is due to its high anthropophily, which explains its efficiency in malaria transmission [17]. Vector abundance varied seasonally and increased with increasing rainfall, resulting in the proliferation of An. gambiae populations. The presence of An. rufipes, a better known zoophilic species [17], and other non malaria vectors is indicative of the level of nuisance that inhabitants of these areas get from these mosquitoes.

Interestingly, An. melas was absent amongst the human biting populations of the An. gambiae complex but occurred in the samples reared from wild larvae from Limbe and Idenau. Unlike in many areas along the coast of West Africa where it is reported to be an important malaria vector [34-36], An. melas appears not to play a role in malaria transmission in coastal Cameroon.

Anopheles melas was identified from breeding sources within $2 \mathrm{~km}$ from the coastline in Idenau and within 3 to $5 \mathrm{~km}$ from the coastline in Limbe. Its absence in Tiko may be due to several reasons ranging from human, climatic and ecological determinants such as reduction in the salt content or complete absence of saline water as distance from the coastline increases. With rapid growth in population, urbanization and agro-industrial activities within the $\mathrm{CDC}$, this area has been deprived of its mangrove swamps that are preferential for An. melas breeding [36].

The observed parity rates were high. This indicates that older populations of mosquitoes tend to accumulate with time. This allows for increased feeding frequencies and thus, increased chances of the vectors becoming infected or even re-infected during subsequent feeding [37].

Although the infection rates (CSA rates) for An. gambiae showed high susceptibility to $P$. falciparum infection, the mean CSA rates for An. funestus were generally higher despite the small numbers. This is due to the marked affinity An. funestus has to humans and their dwellings, thus increasing their chances of becoming infected [38]. This does not, however, underestimate the role of An. nili having relatively high infection rates in this area. To minimize false positive CSA ELISA, only the heads and thoraxes were used and the presence of sporozoites was confirmed by PCR $[27,28,39]$. Thus, CSA rates were calculated using only specimens confirmed positive by PCR. The ability of An. gambiae to support the development and propagation of more than one parasite species at the same time is indicative that it can transmit more than one parasite species simultaneously, as earlier demonstrated in other areas of Africa [40,41]. The sporozoite densities in this study were lower than was reported in western Kenya and in Tanzania, implying that the number of heavy infections were smaller than the number of light infections $[42,43]$.

Malaria transmission dynamics have been shown to vary greatly across Africa [14]. Mean annual inoculation rates vary from less than one to over $1,000 \mathrm{ib} / \mathrm{p} / \mathrm{y}[44,45]$. The observed mean annual inoculation rates in Tiko, Limbe and Idenau are therefore high and corroborate previous studies in other parts of Cameroon [5,33,46-48]. Despite the higher infection rates observed for An. funestus, the EIR for An. gambiae was generally higher. This is probably due to a multiplier effect of the high density and biting rate of 
An. gambiae, an observation similar to that in coastal Tanzania [42].

\section{Conclusion}

Transmission in coastal Cameroon occurs perennially with the periodicity of heightened entomological inoculation rates coinciding with periods of increased vector density, biting rates, prevalence of malaria parasitaemia in the indigenous population and rainfall. Anopheles melas, apart from constituting only a minor proportion of the An. gambiae complex, was not anthropophagic, and therefore not an important vector in the surveyed areas. The findings provide a baseline for evidence-based planning and implementation of malaria control activities.

\section{Authors' contributions}

JDB: Conception of study and experimental design, data collection, analysis and interpretation, preparation of the manuscript. LM: Contributed substantially to conception, study design, interpretation of data, and critically reading the manuscript for important intellectual content. VPKT: Contributed to designing and interpretation of the data as well as critically revising the manuscript. MC: Experimental design of the study and critically revised manuscript for intellectual content. RGFL: Participation in study design and coordination. Interpretation of the data, critically reading of the manuscript. All authors read and approved the manuscript.

\section{Acknowledgements}

This work received financial assistance from UNDP/world Bank/WHO special programme for Research and Training in tropical diseases $\mathrm{N}^{\circ}$. M8//8I/ 4/B.308 and the National Institutes of Health (NIH) funded Human Immune Response to malaria in Endemic areas - International Collaboration in Infectious Disease Research (HIRE-ICIDR) malaria Project No.UOIAl 135839, MD USA. We are indebted to the authorities of the Cameroon Development Corporation (CDC), the population and study participants in Tiko (Small lkange), Limbe (Middle farms) and Idenau (Scipio/Bibundi) for the frank collaboration. Sporozoite ELISA monoclonal antibodies were donated by Robert Wirtz (CDC Atlanta) of the NIH, USA. We thank the research team of the Immunology laboratory at the Biotechnology Center, University of Yaounde I for technical and material support.

\section{References}

I. Mfonfu D: Proceedings on the conference of "malaria in Africa: practical considerations on malaria and clinical trials" Washington DC: Am Inst Biol Scs; 1986:103-112.

2. Titanji VPK, Nkuo-Akenji T, Ntopi W, Djokam R: Reduced levels of chloroquine resistant Plasmodium falciparum in selected foci of the South West province, Cameroon. Cent Afr J Med 200I, 47: I45-I 49.

3. Mvondo JL: Malaria in Cameroon. Training Reports for TWF investigators (August-September) 1998.

4. WHO/CAMINFOS: Lutte contre le paludisme. Le Cameroun déroule son plan stratégique 2002-2006 2002.

5. Quakyi IA, Leke RG, Befidi-Mengue R, Tsafack M, Bomba-Nkolo D, Manga L, Tchinda V, Njeungue E, Kouontchou S, Fogako J, Nyonglema P, Harun LT, Djokam R, Sama G, Eno A, Megnekou R, Metenou S, Ndoutse L, Same-Ekobo A, Alake G, Meli J, Ngu J, Tietche F, Lohoue J, Mvondo JL, Wansi E, Leke R, Folefack A, Bigoga J, Bomba-Nkolo C, Titanji V, Walker-Abbey A, Hickey MA, Johnson AH, Taylor DW: The epidemiology of Plasmodium falciparum malaria in two
Cameroonian villages: Simbok and Etoa. Am J Trop Med Hyg 2000, 63:222-230.

6. Etang J, Manga L, Chandre F, Guillet P, Fondjo E, Mimpfoundi R, Toto JC, Fontenille D: Insecticide susceptibility status of Anopheles gambiae s.l. (Diptera: Culicidae) in the Republic of Cameroon. J Med Entomol 2003, 40:49I-497.

7. Manga L, Bouchite B, Toto JC, Froment A: Anopheles species and the transmission of malaria in the forest/savannah transition zone in central Cameroon. Bull Soc Path Exot 1993, 90:128-130.

8. Antonio-Nkonjio C, Kerah CH, Simard F, Awono-Ambene P, Chouaibou M, Tchuinkam T, Fontenille D: Complexity of malaria vectorial system in Cameroon: contribution of secondary vectors to malaria transmission. J Med Entomol 2006, 43:|2| I5-I22I.

9. Fondjo E: Etude du comportement du complexe Anopheles gambiae et de la transmission du paludisme dans deux faciès éco-climatique au Mali et au Cameroun Thèse de 3ème Cycle, Unversité de Bamako; 1996:93.

10. Carnevale P, Le Goff G, Toto JC, Robert V: Anopheles nili as the main malaria vector in villages of Southern Cameroon. Med Vet Entomol 1992, 6:135-138.

II. Manga L, Toto HC, Le Goff G, Brunhes J: The bionomics of Anopheles funestus and its role in malaria transmission in a forested area of Southern Cameroon. Trans R Soc Trop Med Hyg 1997, 91:387-388.

12. Fondjo E, Robert V, Le Goff G, Toto JC, Carnevale P: Urban malaria transmission in Yaounde (Cameroon). 2. Entomologic study in 2 semi urban districts. Bull Soc Path Exot 1992, 85:57-63.

13. Njan-Nloga A, Robet V, Toto JC, Carnevale P: Le cycle gonotrophique d' Anopheles moucheti, vecteur principal du paludisme au Sud Cameroun. Bull Liaison Doc OCEAC 1993, 26:28-7I.

14. Fontenille D, Simard F: Unraveling complexities in human malaria transmission dynamics in Africa through a comprehensive knowledge of vector populations. Comp Immunol Microbiol Infect Dis 2004, 27:357-375.

15. Wanji S, Tanke T, Atanga SN, Ajonina C, Tendongfor N, Fontenille D: Anopheles species of the mount Cameroon region: biting habits, feeding behaviour and entomological inoculation rates. Trop Med Int Health 2003, 8:643-649.

16. Wondji C, Frederic S, Petrarca V, Etang J, Santolamazza F, Della Torre A, Fontenille D: Species and populations of the Anopheles gambiae complex in Cameroon with special emphasis on chromosomal and molecular forms of Anopheles gambiae s.s. J Med Entomol 2005, 42:998-1005.

17. Gillies MT, De Meillon B: The Anophelinae of Africa South of the Sahara Publication of the South African Institute for Medical Research, Johannesburg; 1968:54.

18. Gillies MT, Coetzee M: A Supplement to the Anophelinae of Africa South of the Sahara (Afrotropical region) Publication of the South African Institute for Medical Research, Johannesburg; 1987:55.

19. Detinova TS: Age grouping methods in Diptera of medical importance, with special reference to some vectors of malaria. World Health Organization. Monographs series 1962, 47:216.

20. Scott JA: Identification of single specimens of the Anopheles gambiae complex by the polymerase chain reaction. AmJ Trop Med Hyg 1993, 49:520-529.

21. Favia GA, Della T, Bagayoko M, Lanfrancotti A, Sagnon NF, Touré YT, Coluzzi M: Molecular identification of sympatric chromosomal forms of Anopheles gambiae and further evidence of their reproductive isolation. Insect Mol Biol 1997, 6:377-383.

22. Wirtz RA, Zavala F, Charoenvit Y, Campbell GH, Burkot TR, Schneider I, Esser K, Beaudoin RL, Andre RG: Comparative testing of Plasmodium falciparum sporozoite monoclonal antibodies for ELISA development. Bull World Health Organ 1987, 65:39-45.

23. Burkot TR, Williams JL, Schneider I: Identification of Plasmodium falciparum-infected mosquitoes by a double antibody enzyme-linked Immunosorbent assay. Am J Trop Med Hyg 1984, 33:783-788.

24. Beier JC, Asiago CM, Onyango FK, Gargan TP, Wirtz RA, Koech DK, Roberts CR: ELISA absorbance cut-off method affects malaria sporozoite rate determination in wild Afrotropical Anopheles. Med Vet Entomol 1988, 2:259-264.

25. Snounou G, Viriyakosol S, Zhu XP, Jarra W, Pinheiro L, Rosario VE, Thiathong S, Brown NK: High sensitivity detection of human malaria parasites by the use of nested polymerase chain reaction. Mol Biochem Parasitol 1993, 6 1:3 15-320. 
26. Tassanakajon A, Boonsaeng V, Wilairat P, Panyim S: Polymerase chain reaction detection of Plasmodium falciparum in mosquitoes. Trans R Soc Trop Med Hyg 1993, 87: I73-I75.

27. Lochouarn L, Fontenille D: ELISA detection of malaria sporozoites: False positive results in Anopheles gambiae s.I. associated with bovine blood meals. Trans R Soc Trop Med Hyg 1999, 93: $101-102$

28. Somboon P, Morakote N, Kootathep S, Trsanarom U: Detection of sporozoites of Plasmodium vivax and Plasmodium falciparum in mosquitoes by ELISA: false positivity associated with bovine and swine blood. Trans R Soc Trop Med Hyg 1993, 87:322-332.

29. World Health Organization: Manual of basic techniques for a health laboratory World Health Organization, Geneva. Switzerland; 1980.

30. Plowe CV, Djimde A, Bouare M, Doumbo O, Wellems TE: Pyrimethamine and Proguanil resistance conferring mutationin Plasmodium falciparum dihydrofolate reductase: polymerase chain reaction methods for surveillance in Africa. Am J Trop Med Hyg 1995, 52:565-568.

31. Patz J, Balbus J: Methods for assessing public health vulnerability to global climate change. Climate Research 1996, 6: I I3-I25.

32. Manga L, Bouchite B, Toto JC, Froment A: Anopheles species and the transmission of malaria in the forest/savannah transition zone in central Cameroon. Bull Soc Path Exot I993, 90: I28-I30.

33. Manga L: Environments, Vecteurs et transmission du paludisme en milieux urbain et rural de la zone forestieres du Sud Cameroun. Thèse pour obtenir le grade de docteur de l'Université Montpellier 1999.

34. Diop A, Molez JF, Konate L, Fontenille D, Gaye O, Diouf M, Diagne $M$, Faye O: Role of Anopheles melas Theobald (1903) on malaria transmission in a mangrove swamp in Senegal. Parasite 2002, 9:239-246.

35. Akogbeto M: Le paludisme côtier lagunaire à Cotonou: données entomologiques. Cahiers d'études et de recherches francophones/Santé 2000, 10:267-275.

36. Greenwood BM: The epidemiology of malaria. Ann Trop Med Parasitol 1997, 91:763-769.

37. Service MW: Mosquito ecology: Field sampling methods London: Applied Science publishers; 1976.

38. White GB: Anopheles gambiae complex and disease transmission in Africa. Trans R Soc Trop Med Hyg 1974, 68:278-298.

39. Robert $V$, Van den Broek A, Stevens P, Slootweg R, Petrarca $V$, Coluzzi M, Le Goff G, Di Deco, Carnevale P: Mosquitoes and malaria transmission in irrigated rice fields in the Benoue valley of northern Cameroon. Acta Trop 1992, 52:201-204.

40. McKenzie FE, Bossert WH: Mixed species Plasmodium infections of Anopheles (Diptera: Culicidae). J Med Entomol 1987, 34:417-425.

4I. Arez AP, Palson K, Pinto J, Franco AS, Dinis J, Jaenson TG, Snounou $G$, do Rosario VE: Transmission of mixed malaria species and strains by mosquitoes, as detected by PCR, in a study area in Guinea Bissau. Parassitologia 1997, 39:65-70.

42. Pringle G: A quantitative study of naturally acquired malaria infections in Anopheles gambiae and Anopheles funestus in a highly malarious area of East Africa. Trans $R$ Soc Trop Med Hyg 1996, 60:626-632.

43. Temu EA, Minjas JN, Coetzee M, Hunt RH, Shiff CJ: The role of four anopheline species (Diptera: Culicidae) in malaria transmission in coastal Tanzania. Trans R Soc Trop Med Hyg 1998, 92: $152-158$.

44. Beier JC, Killeen GF, Githure Jl: Short report: entomologic inoculation rates and Plasmodium falciparum malaria prevalence in Africa. Am J Trop Med Hyg 1999, $61: 9-13$.

45. Hay SI, Rogers DJ, Toomer JF, Snow RW: Annual Plasmodium falciparum entomological inoculation rates (EIR) across Africa: literature survey, Internet access and review. Trans $R$ Soc Trop Med Hyg 2000, 94: I I3-I 27.

46. Antonio-Nkondjio C, Simard F, Awono-Ambene P, Ngassam P, Toto JC, Tchuinkam T, Fontenille D: Malaria vectors and urbanization in the equatorial forest region of south Cameroon. Trans $R$ Soc Trop Med Hyg 2005, 99:347-354.

47. Fondjo E, Bigoga JD, Leke RGF, Patchoke S, Kollo B, Dao A, Golenda C, Wirtz RA, Quakyi IA: Malaria transmission in Far Northern Cameroon: Characterization of anopheline species and the sporozoite infection rate. J Cam Acad Sc 2002, 2(suppl):22IS-226S.
48. Cohuet A, Simard F, Wondji CS, Antonio-Nkondjio C, AwonoAmbene $P$, Fontenille $D$ : High malaria transmission intensity due to Anopheles funestus (Diptera: Culicidae) in a village of savannah-forest transition area in Cameroon. J Med Entomol 2004, 4I:901-905.
Publish with Biomed Central and every scientist can read your work free of charge

"BioMed Central will be the most significant development for disseminating the results of biomedical research in our lifetime. " Sir Paul Nurse, Cancer Research UK

Your research papers will be:

- available free of charge to the entire biomedical community

- peer reviewed and published immediately upon acceptance

- cited in PubMed and archived on PubMed Central

- yours - you keep the copyright

Submit your manuscript here:

http://www.biomedcentral.com/info/publishing_adv.asp
BiolMedcentral 